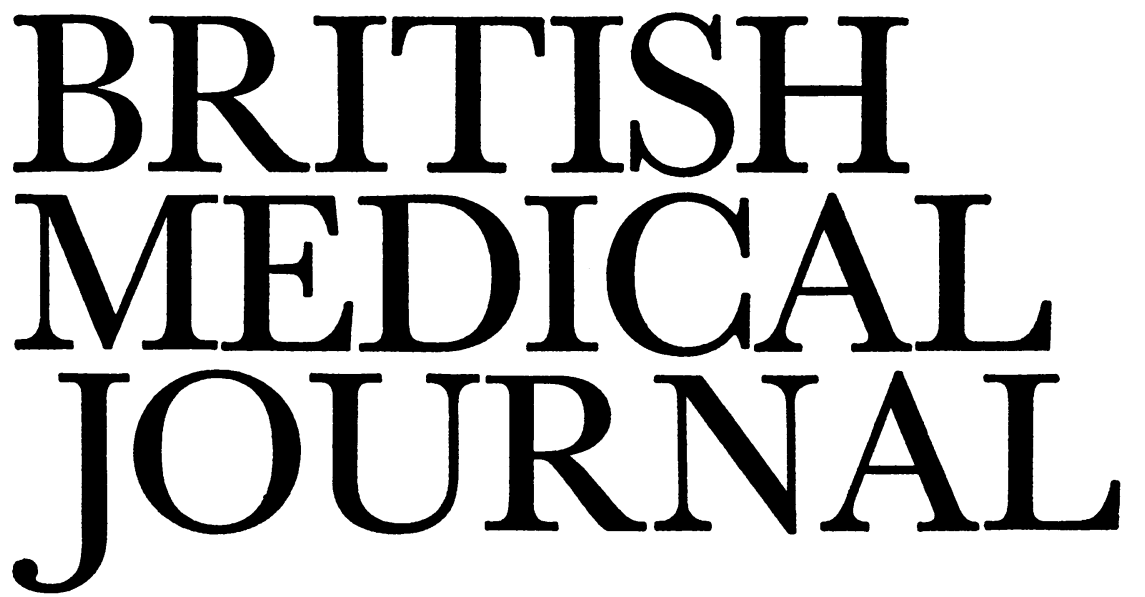

LONDON SATURDAY 9 JUNE 1973

\title{
Looking at Violence
}

Attention has been called again to the possible adverse effects of the mass communication media on children. B. H. Kniveton and J. M. Stephenson ${ }^{1}$ conclude from laboratory experiments with children of 5 to 6 years old that "Children will consistently imitate aggressive filmed models".

Children on two occasions at least four months apart were shown films portraying different aggressive acts, by different models approximately of their own age, and in different settings. There was a highly significant positive correlation between the imitative response to the two films, suggesting an "enduring individual characteristic". It was also shown that increases in aggression occurred consistently over and above the initial tendency to behave in that way. In view of the long periods spent by children in looking at television this and other experimental work deserves attention. These same investigators have earlier ${ }^{2}$ suggested that children "with few interests of their own" are likely to be more susceptible to the influence of filmed or televised models than children with more extensive interests. This reflects the broader conclusions of the two classical studies in this field, ${ }^{34}$ which indicated that sorts of children use sorts of programmes in their own way, and that, while the majority can build the medium into their lives in a balanced manner, some lonely and handicapped children become excessive, habitual viewers.

That children will imitate aggressive models will surprise no one, let alone doctors who are trained to observe. Imitation is only a form of learning, and we know that childhood is a time of intensive learning, much of it-for example, language and vocabulary-necessarily acquired by imitation. Children playing can observe and reproduce sometimes with gratifying, scmetimes with embarrassing, accuracy the mannerisms and actions of their parents. Work with chimpanzees and baboons in East Africa demonstrates the importances of the triad "observation, imitation, practice" in the development of primate behaviour. ${ }^{5}$

But obervational learning is not quite the same as imitation. ${ }^{6}$ Observational learning is a social phenomenon which might result in avoidance rather than imitation; imitation is "a change in behaviour acquired as a result of observing the bebaviour of a person or an animal or of an inanimate occurrence (e.g. a sound)". Modeling is held to be "a sub- class of both imitation and of observation learning, but not synonymous with either." These niceties of definition explain some of the great difficulties which hamper experimental work in this field and which make firm conclusions so tenuous. For example, in Kniveton and Stephenson's study of 1973 the children were transferred to the department of psychology, observed in a play-room one by one, exposed to a short film of a small boy behaving in an aggressive manner, returned to the play-room containing play material similar to that shown in the film, and their behaviour before and after the film analysed in time and quality, and then compared. Throughout the procedure the child was accompanied by a woman assistant who sat in the corner occupied with a paper and pencil and giving no attention to the child (that is, not overtly responding) unless insistently approached. The whole procedure was repeated later on.

This seems as simple a plan as possible, and yet all sorts of complications may be present. For example, that the assistant does not participate and does not react to the first tentative aggressive moves (which will perhaps be made with one eye on the adult) may be construed as approval or at least licence. In accordance with the child's previous experience of adult responses to his aggression he may enjoy it or may feel guilty about it and perhaps try to find the limits of tolerance. Alternatively, like prisoners of war who repress their aggression in the presence of their captors only to release it later on, ${ }^{7}$ some children may store the experience for a more appropriate moment. While it is no criticism of the experimental model, which must start from first principles, it does need to be remembered that much learning is in social situations, and what is true for subjects of one age or sex may not be so for another. We are perhaps rather naive in our appreciation of the extent to which children can size up the situation and adjust to the experiment in what may be an artificial manner.

Experimental work, much of it with children or undergraduates, has been carried out in the last ten years in this field, and the effect of film violence on subsequent aggressive responses has been studied.8-11 In general the conclusion is that brief exposure to unpunished violence in films increases the subject's subsequent aggressive behaviour des- 
pite societal prohibitions. The effect is even more positive in people who have been angered or frustrated first. ${ }^{12} 13$ Berkowitz holds that exposure to film violence produces aggressive behaviour only in aroused subjects and if the appropriate cues are present also in the testing situation. A. $M$. Doob and R. J. Climie ${ }^{14}$ have shown that the effects of filminduced violence in the laboratory are short-lived. $R$. Baron $^{15}$ has produced a series of papers assessing various factors which might reduce the influence of an aggressive model.

S. Rachman in his excellent paper ${ }^{6}$ regards the fear-reducing value of therapeutic modeling (in which films and television can play a part) as convincingly demonstrated. It seems clear that even if television violence is ultimately proved, as seems likely, to have a damaging effect on some individuals, especially if frequently repeated, yet the positive potentialties for therapy, preparation, education, and prevention through social training may be even more striking.

1 Kniveton, B. H., and Stephenson, J. M., British fournal of Psychiatry,

1973, 122, 53.
Kniveton, B. H., and Stephenson, J. M., British Fournal of Social Psycho$\log y, 1970,9,31$.

Himmelweit, H. T., Oppenheim, H. M., and Vince, P., Television and the Child. Nuffield Foundation, London, Oxford University Press, 1958.

Schramm, W., Lyle, J., and Parker, E. B., Television in the Lives of our Children. London, Oxford University Press, 1961.

5 Hamburg, D. A., Sir George Vickers Lecture for the Mental Health Research Fund, Stanford University, 18 February 1970.

6 Rachman, S., Behaviour Therapy, 1972, 3, 379.

Katz, C. J., Mental Hygiene, 1950, 34, 90.

Bandura, A., Ross, D., and Ross, S., Fournal of Abnormal and Social Psychology, 1961, 66, 3.

Bandura, A., in Advances in Experimental and Social Psychology, Vol. 2, ed. L. Berkowitz. New York, Academic Press, 1965.

10 Goranson, R. E., in Advances in Experimental and Social Psychology, Vol. 5, ed. L. Berkowitz. New York, Academic Press, 1970.

11 Singer, J. L., in The Control and Aggression of Violence, ed. J. L. Singer. New York, Academic Press, 1971.

12 Berkowitz, L., Fournal of Personality and Social Psychology, 1965, 2, 359.

18 Berkowitz, L., and Geen, R. G., Fournal of Personality and Social Psycho$\log y, 1967,5,364$.

14 Doob, A. M., and Climie, R. J., Journal of Experimental Social Psychology,

15 Baron, R. A., fournal of Personality and Social Psychology, 1971, $20,240$.

\section{Carcinoma of the Prostate}

In 1970 out of 63,236 deaths of males from cancer in England and Wales 3,906 were recorded as due to carcinoma of the prostate. ${ }^{1}$ This places prostatic cancer as the fourth most common cause of cancer death in the male. While the incidence of clinical prostatic cancer fluctuates widely throughout the world, in the urbanized communities of the western hemisphere it is broadly similar to that in Great Britain. ${ }^{2}$ Thus it is appropriate that the subject of prostatic cancer should have been chosen as one of the key topics at the American Cancer Society's National Congress on Urologic Cancer held in Washington D.C. in March. A general impression of this conference is that it surveyed the best current views on aetiology, pathology, and therapy, but that in recent years no real advances have emerged.

Three aetiological factors appeared to be important, though little detailed knowledge exists about any of them. Firstly, hormones are considered to be of primary importance, but on very slender evidence. Probably the hormonal state of the patient is of paramount importance in stimulating and maintaining the prostatic epithelium, though hormones themselves appear to play no part in the actual genesis of the tumour. ${ }^{3}$ Tumour clls, however, like the cells of the adult prostate, may remain dependent on hor- mones. Prostatic cancer appears to bear no relationship to oestrogen levels or the level of adrenal hormones, nor do we know whether the pituitary plays any part in it or not. One of the principal problems in hormonal studies is that most of the investigations have been done on patients who already have the disease, and so the changes which induced the tumour may have occurred years before.

Secondly, age has a bearing on the disease. While it is rare before 50 , the disease thereafter increases rapidly in incidence to 80 , and then slows, so that prostatic carcinoma is the most important cancer in the older age groups.

The third important aetiological factor is race. The incidence ranges from the highest for negroes in Alameda County, U.S.A., to the generally very low figures noted in oriental races. There appears to be a genuinely high incidence in New Zealanders, both white and Maoris, and in the Scandinavian countries. Environment appears to be of some importance in this connexion because the incidence is higher in Japanese residents in the United States than in Japan but does not rise to Caucasian levels. ${ }^{4}$

It is important that nomenclature should be correct and uniform. Prostatic cancers are divided into clinical, latent, and occult. Clinical prostatic cancer is when the disease is producing symptoms and is diagnosed by histology. Latent cancers are those foci, morphologically resembling prostatic cancer, which do not themselves produce symptoms. They are usually found incidentally at prostatectomy or necropsy and have not at that time disseminated. Occult cancers are those which produce metastases while the primary remains insignificant in size or hidden. In discussion of the natural history of the disease and the effects of treatment the staging of prostatic cancer is of great importance. The tendency is to use the American classification rather than that of the International Union against Cancer (U.I.C.C.), which is undergoing revision. The American classification has four stages A, B, C, and D. Stage A covers the occult cancers. Stage B cancer is confined within the prostatic capsule; this covers the latent cancers and some small clinical tumours. In stage $\mathbf{C}$ the disease has spread outside the capsule, with extension into surrounding structures, or is confined to the capsule with elevation of the serum acid phosphatase level. In stage $D$ the tumour has produced demonstrable bony or extra-pelvic metastases.

The biological significance of latent prostatic cancer is still debatable. It is not known whether the foci and nodules represent early cancer which has not yet become clinically developed, or whether they are a distinct disease and will not under normal circumstances develop into clinically active cancer. The fact that latent cancers increase with age would appear to indicate that the latter supposition is the more correct. 5

There is still no universally approved treatment, and current practice ranges from radical surgery to conservative treatment only. A small school of thought favours radical prostatectomy for a select group of cases, but these make a very small part of the whole. ${ }^{6}$ With careful selection of patients this operation, which carries the penalty of total impotence, has given a $90 \%$ 10-year survival rate in those patients whose lesions were less than $1 \mathrm{~cm}$ in diameter. But when the lesions rise to $2 \mathrm{~cm}$ in diameter only $67 \%$ of the patients are alive at 10 years. For the bulk of cases transurethral resection will be needed to overcome obstruction of the urinary tract, while to deal with the complications of locally growing and disseminating cancer the use of 